\title{
Impact of Living Condition on Mental Health During Lockdown: An Empirical Analysis
}

\section{Utpal Pal ${ }^{1}$, Manas Ku. Sethi' ${ }^{2}$, Sharmistha Bhowmik ${ }^{3}$, Alpha Rajeswari Patra ${ }^{4}$ Saptami Pal', Subodh Pal ${ }^{6}$}

\author{
'Research Scholar, Tezpur University, Tezpur, Assam 784028, India; '2lecturer in Commerce, Sanda Degree College, Dhenkanal-759020, India; \\ ${ }^{3}$ Pursuing BLIS, 1GNOU, Bhubaneswar 751025, Odisha, India; ${ }^{4}$ Trainer at DDU-GKY, Bhubaneswar-752101, Odisha, lndia; ${ }^{5 \mathrm{M} J M C}$ Student, Utkal \\ University, Bhubaneswar-752101, Odisha, India; ${ }^{6}$ Mcom Student (F\&C), IMS, Bhubaneswar 752101, Odisha, India.

\section{ABSTRACT}

Background: The spread of Corona disease has created different types of speculation in the mind of every human being. The World Health Organisation (WHO) declared it as a Pandemic. To control the multiplicity of this virus, the Govt. of India declaredlockdown from $25^{\text {th }}$ March-2020 and now it is in the unlock stage. During this nationwide lockdown, people all over the country are not able to move from one place to another. As a result, some persons have been living alone for a long time. They are deprived of meeting their near and dear ones.

Objectives: This study aims at understanding the relationship between the living conditions of a person during lockdown with the different aspect of mental health; such as level of depression, level of anxiety and level of stress.

Methods: Convenient Sampling is used for data collection through structured e-questionnaire. Chi-Square Test is used to study the level of significance among the different category of variables.

Results: The analysis shows that $p=0.003$ between living condition and level of depression, $p=0.036$ between living condition and Level of anxiety and $p=0.004$ between living condition and level of stress.

Conclusion: The living condition a person affects mental health. It has a great effect on the level of depression, anxiety and stress. The mental well being should be maintained with proper stress management activities.

Key Words: Mental health, Lockdown, Depression, Anxiety, Stress

\section{INTRODUCTION}

In India, the first confirmed Covid-19 positive case was reported on January 30 in Kerala. The Govt. of India declared lockdown from $25^{\text {th }}$ March-2020 after "Corona Virus has been declared as a pandemic by the World Health Organisation (WHO) on $11^{\text {th }}$ March-2020. ${ }^{1}$ With the aim of controlling the extent of this disease, the lockdown goes on extension and now it is in the fifth phase. "The Govt. of India is taking all necessary steps to counter the challenge and threat posed by the mounting pandemic of Corona Virus. With dynamic support of the citizens of India, the Govt. of India has been able to restrain the extent of the Virus in the country. ${ }^{2}$

During this nationwide lockdown, most of the people are unable to move from one place to another due to restriction in inter-state and intra-state transportation. ${ }^{3}$ Some of them are living along with their family member and spending valuable time with their loved ones. However, this lockdown affects adversely those who are living alone and far away from their family members. As a result, people are suffering from depression, anxiety, and stress. Some are involved in different types of activities to overcome the negativity of the pandemic situation. Some are living as usual and some are involving themselves in social work. The activities undertaken for stress management are listening to music, watching videos, doing exercises, reading books etc.

Depression may be a disposition clutter that includes a diligent feeling of pity and misfortune of intrigued. It is distinctive from the disposition changes that individuals frequently encounter as a portion of life. ${ }^{5}$ Stress could be a reaction to everyday pressures or an undermining circumstance, where-

\section{Corresponding Author:}

Utpal Pal, Research Scholar, Tezpur University, Tezpur, Assam, 784028, India. Phone: 7008776252; Email: utpalpalbabu@gmail.com; ORCID ID-https://orcid.org/0000-0003-0443-8950

ISSN: 2231-2196 (Print)

Received: 18.07.2020
ISSN: $0975-5241$ (Online)

Revised: 21.09 .2020
Accepted: 11.11 .2020
Published: 07.12 .2020 
as uneasiness may be a response to the push. Uneasiness, which has no clear cause, tends to final longer and be more troublesome to treat. ${ }^{1}$

After reviewing the above-mentioned articles, it is observed that different authors have given their opinion on mental health during the pandemic situation in their study area. Some of them have used primary data and some through secondary data. Some authors used a statistical technique like regression model and some used factor analysis. ${ }^{6}$ So, the present study focuses on the gap that arises due to the study area. This paper is based aims at studying the living condition and its impact on mental well being of the various persons from different parts of India. ${ }^{7}$ This paper aims at understanding the impact of the living condition on mental well being during the lockdown, the Level of depression, anxiety and stress level among the respondents and to focus on the activities undertaken for positive mental health during the lockdown.

\section{MATERIALS AND METHODS}

\section{Data Sources}

Data are collected from the primary as well as secondary sources for the entire study. Primary Data is collected through a structured questionnaire via a google form. Secondary data is collected from the published articles, Govt. Websites, and e-articles of different private agencies.

\section{Sample Design, Size and Coverage Area}

The Convenient sampling technique is used for the study. Total 80 sample has collected for the study. The Sampling instrument used for data collection is structured e-Questionnaire. The samples are collected from the respondents of Assam and Odisha, India.

\section{Statistical Technique Used}

The frequency tables, descriptive statistics and chi-square test are used for data analysis and interpretation as per the objectives and hypotheses.

\section{Variables}

The Independent Variable is Living condition (Whether living alone or not?) and dependent variables are the level of depression, anxiety and stress.

\section{RESULTS}

\section{The demographic factors and responses to the different variable}

From the above diagram, $40 \%$ of the respondents are from 26-35years and almost 39\% are from 18-25 years old. The $3^{\text {rd }}$ highest responses received from $36-45$ years age group. The least number is respondents are from the age group 46 to 55 years and no response received from the age group above 55 years (Figure 1A). Out of the total respondents, $62.5 \%$ i.e., 50 respondents are male and $37.5 \%$ i.e., 30 respondents are female (Figure 1B). From the total respondents, $41 \%$ are students/research scholars. $25 \%$ are government employees, $20 \%$ are businessman, $10 \%$ are private employees and only 4\% are retired persons (Figure 1C). Out of the total respondents, only $21.3 \%$ are staying alone at far away from their family during this lockdown and $78.8 \%$ are staying with their family members during this lockdown (Figure 1D).

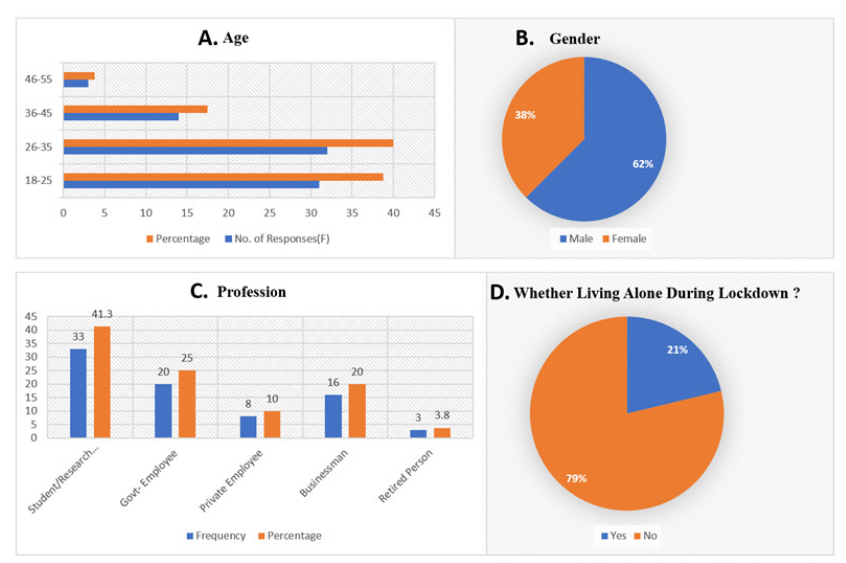

Figure 1: Demographic characteristics of the participants. A. Age-wise distribution of patients, B. Gende-wise distribustion, C. Classification based on profession and D. living status during lockdown.

\section{Effect on the mental behaviour}

Figure $2 \mathrm{~A}$ depicts that $53.8 \%$ are moderately suffering from depression, $35 \%$ are normal and $11.3 \%$ are suffering from severe level of depression during this lockdown. It is clear that $50 \%$ of respondents are suffering from a moderate level of anxiety, $38.8 \%$ are normal and only $11.3 \%$ are suffering from a severe level of anxiety (Figure 2B). Figure 2C showed that $50 \%$ of respondents are suffering from a moderate level of stress, $33.8 \%$ are normal and $16.3 \%$ are suffering from severe stress during the lockdown.

\section{Identificantion of activities for stress manage- ment}

Figure 3 shows that $33.8 \%$ are learning new skills during the lockdown, $31.3 \%$ are spending time by listening to music and viewing videos. $17.5 \%$ are doing yoga/exercise and $10 \%$ are engaging themselves in reading \& writing more and only $5 \%$ are engaged in other activities for stress management. 


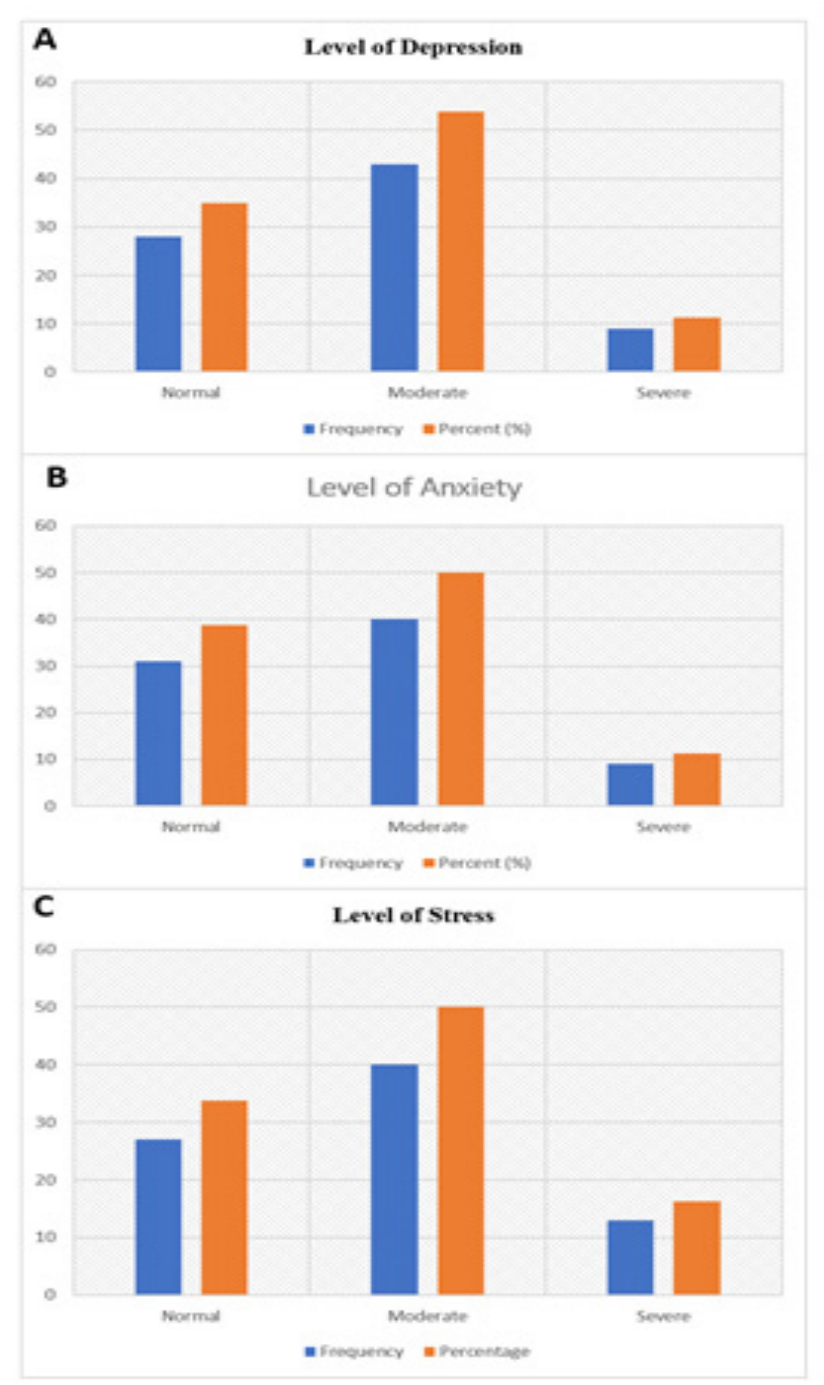

Figure 2: Represents level of depression (A), anxiety (B) and stress (C).

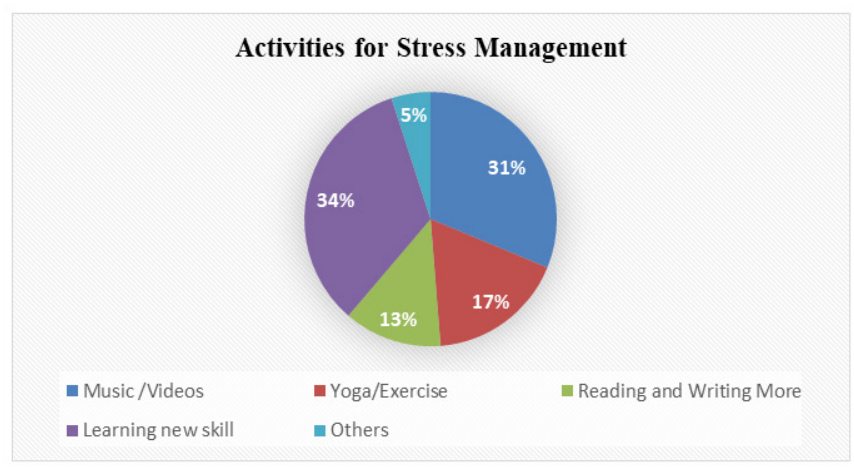

Figure 3: Represents different activities taken up for the stress management.

Table 1 indicates a side-by-side comparison of the descriptive statistics of the variables understudied. This helps us in making the following observations about the data:

- The total number of observation (N)is 80 .

- The variables having the highest average is Activity for stress management i.e., 2.64, the second-highest in the profession's average i.e., 2.20 and averages of other variables are closely related.

- The Standard errors of all variables are very close.

- The highest value of standard deviation is 1.362 and the lowest value is 0.412 .

- The highest variance lies inactivity for stress management i.e., 1.854 .

Inspecting tables 2 and 3, it appears that the two variables, a living condition during lockdown and level of depression are connected. As $\mathrm{p}=0.003$, so the null hypotheses are rejected. It is concluded that living condition and level of depression during the lockdown.

\section{Table 1: Descriptive Statistic}

\begin{tabular}{lccccc} 
& No. of Responses & \multicolumn{2}{c}{ Arithmetic Average } & $\begin{array}{c}\text { Standard } \\
\text { Deviation }\end{array}$ & Variance \\
& Statistic & Statistic & Standard Error & Statistic & Statistic \\
Age & 80 & 1.86 & .094 & .838 & .702 \\
Gender & 80 & 1.38 & .054 & .487 & .237 \\
Profession & 80 & 2.20 & .143 & 1.277 & 1.630 \\
Whether Living Alone? & 80 & 1.79 & .046 & .412 & .169 \\
Level of Depression & 80 & 1.76 & .072 & .641 & .411 \\
Level of Anxiety & 80 & 1.73 & .073 & .656 & .430 \\
Level of Stress & 80 & 1.83 & .077 & .689 & .475 \\
Activity for Stress Mgt. & 80 & 2.64 & .152 & 1.362 & 1.854 \\
Valid N (list-wise) & 80 & & & & \\
\hline
\end{tabular}


Table 2: Cross tabulation (Whether Living Alone * Level of Depression)

\begin{tabular}{lclcccc} 
& & \multicolumn{2}{c}{ Level of Depression } & \multicolumn{2}{c}{ Total } \\
Whether Living & Yes & Count & Normal & Moderate & Severe & 17 \\
Alone? & & 0 & 14 & 3 & 17.0 \\
& & Expected Count & 6.0 & 9.1 & 1.9 & 63 \\
& No & Count & 28 & 29 & 6 & 63.0 \\
Total & & Expected Count & 22.1 & 33.9 & 7.1 & 80 \\
& & Count & 28 & 43 & 9 & 80.0 \\
\hline
\end{tabular}

Table 3: Chi-Square Tests

\begin{tabular}{lccc} 
& Value & Degree of freedom & Asymp. Sig. (2-sided) \\
Pearson's Chi-Square & $11.627^{\mathrm{a}}$ & 2 & .003 \\
Likelihood-Ratio & 17.036 & 2 & .000 \\
Linear-by-Linear Associations & 8.996 & 1 & .003 \\
Valid Cases (N) & 80 & & \\
\hline
\end{tabular}

Inspecting tables 4 and 5, it appears that the two variables, a living condition during lockdown and level of anxiety are related. As $\mathrm{p}=0.036$, so the null hypotheses are rejected. There- fore, a person's living condition and level of anxiety during a lockdown.

Table 4: Crosstab(Whether Living Alone *Level of Anxiety)

\begin{tabular}{|c|c|c|c|c|c|c|}
\hline & & & \multicolumn{3}{|c|}{ Level of Anxiety } & \multirow[t]{2}{*}{ Total } \\
\hline & & & Normal & Moderate & Severe & \\
\hline \multirow[t]{4}{*}{ Whether Living Alone? } & Yes & Count & 2 & 12 & 3 & 17 \\
\hline & & Expected Count & 6.6 & 8.5 & 1.9 & 17.0 \\
\hline & No & Count & 29 & 28 & 6 & 63 \\
\hline & & Expected Count & $24 \cdot 4$ & 31.5 & 7.1 & 63.0 \\
\hline \multirow[t]{2}{*}{ Total } & & Count & 31 & 40 & 9 & 80 \\
\hline & & Expected Count & 31.0 & 40.0 & 9.0 & 80.0 \\
\hline
\end{tabular}

Table 5: "Chi-Square Tests"

\begin{tabular}{lccc} 
& Value & Degree of freedom & Asymp. Sig. (2-sided) \\
Pearson's Chi-Square & $6.672^{\mathrm{a}}$ & 2 & .036 \\
Likelihood- Ratio & 7.602 & 2 & .022 \\
Linear-by-Linear Associations & 5.598 & 1 & .018 \\
N of Valid Cases & 80 & & \\
\hline
\end{tabular}

Inspecting tables 6 and 7, it is clear that living condition and level of stress are related to each other in some way. As $\mathrm{p}=0.004$, so the null hypotheses are rejected. Therefore, a person's living condition and level of stress during the lockdown. 
Table 6: Crosstab (Whether Living Alone* Level of Stress)

\begin{tabular}{lclcccc} 
& & \multicolumn{2}{c}{ Tevel of Stress } & \multicolumn{2}{c}{ Total } \\
Whether Living & Yes & Count & Normal & Moderate & Severe & 17 \\
Alone? & & 0 & 13 & 4 & 17.0 \\
& No & Count & 5.7 & 8.5 & 2.8 & 63 \\
& & Expected Count & 27 & 27 & 9 & 63.0 \\
Total & & 21.3 & 31.5 & 10.2 & 80 \\
& & Count & 27 & 40 & 13 & 80.0 \\
\hline
\end{tabular}

Table 7: "Chi-Square Tests"

\begin{tabular}{lccc} 
& Value & Degree of freedom & Asymp. Sig. (2-sided) \\
Pearson's Chi-Square & $11.015^{\mathrm{a}}$ & 2 & .004 \\
Likelihood -Ratio & 16.265 & 2 & .000 \\
Linear-by-Linear Associations & 7.646 & 1 & .006 \\
N of Valid Cases & 80 & & \\
\hline
\end{tabular}

\section{DISCUSSION}

By analysing the data and its interpretation, the overall findings of the study are as below:

- Maximum numbers of the respondents are male.

- Most of the responses are lies between 18-35 years.

- The highest numbers of respondents are either students or research scholar.

- Out of the total respondents, most of the Govt. employees are living alone away from their family.

- The value of $p$ is less than 0.05 in all the three hypotheses. Therefore, all the null hypotheses are rejected.

- There is a relationship between the living condition and level of depression during the lockdown.

- Living condition and level of anxiety are also related as per the interpretation of the data.

- Finally, the living condition during lockdown and level of stress are related.

- To manage the level of stress and improve the mental health conditions, people are engaging themselves in different activities like exercise, yoga, writing, reading, watching videos, listening music and learning different new skills.

As the pandemic of coronavirus is still spreading all over the world, so it is not possible to predict its overall impact on mental health. The sample size is very small because it is not possible to reach out to all the respondents. So, the inherent limitations of e-questionnaire are existing in this study. The result may vary by analysing large numbers of sample and in the different study area.

\section{CONCLUSION}

From the above discussion, we conclude that this lockdown affects adversely those who are living alone and far away from their family members. As a result, people are suffering from depression, anxiety, and stress. There is a relationship between the living condition and level of depression during the lockdown. Living condition and level of anxiety are also related as per the interpretation of the data. Finally, the living condition during lockdown and level of stress are related. With the intention of managing the level of stress and improve the mental health conditions, people are engaging themselves in different activities like exercise, yoga, writing, reading, watching videos, listening music and learning different new skills. The Govt. has been taking different steps for the wellbeing of the people at a large as well as Institutional support is provided to the students to maintain positivity and motivate them during this pandemic.

\section{ACKNOWLEDGEMENT}

Authors acknowledge the immense help received from the scholars whose articles are cited and included in references to this manuscript. The authors are also grateful to authors/ editors/publishers of all those articles, journals and books from where the literature for this article has been reviewed and discussed.

\section{Sources of funding: None.}

Conflicts of interest: Nil. 


\section{REFERENCES}

1. Premierhealth. https://www.premierhealth.com/your-health/articles/women-wisdom-wellness-/anxiety-depression-stress-whythe-differences-matter. Retrieved May 25, 2020,

2. Douglas P, Douglas D, Harrigan D. Preparing for pandemic influenza and its aftermath: Mental health issues considered. Int J Emerg Mental Health 2009; 11:137-44.

3. Galderisi S, Heinz A, Kastrup M, Beezhold J, Sartorius N. Toward a new definition of mental health. World Psychiatry 2015; 14(2): 231-233.

4. Krešimir C, Sinisa P, Marko S̆, Ivan K. Impact of Human Disasters and Covid-19 Pandemic on Mental Health: Potential of Digital Psychiatry. Psychiatria Danubina 2020;32(1): 25-31.
5. Shah K, Kamrai D, Mekala H. Focus on Mental Health during the Coronavirus (COVID-19) Pandemic: Applying Learnings from the Past Outbreaks. Cureus 2020; 12(3): e7405.

6. Chittaranjan S. The COVID-19 Pandemic and Chances of a Mental Health Crisis in India. 2020. Retrieved from https://www. researchgate.net/publication/340846093 The_COVID-19_Pandemic_and_Chances_of_a_Mental_Health_Crisis_in_India/ link/5f55c44d458515e96d35cdcd/download. (Accessed on June 2020).

7. Singh OP. Mental health of migrant laborers in COVID-19 pandemic and lockdown: Challenges ahead. Indian J Psychiatry 2020; 62:233-4. 